\title{
THE EFFECTIVENESS OF SOCIAL ADS TARGETING DRUNK DRIVING
}

\author{
Dainora Šakinytė, Rasa Markšaitytė, Laura Šeibokaitė, Auksė Endriulaitienė, \\ \& Justina Slavinskienè \\ Vytautas Magnus University, Jonavos 66-328, Kaunas (Lithuania)
}

\begin{abstract}
Social advertisements with threat appeals are widely used to reduce drunk driving. However, research on the effectiveness of such advertising is limited. This study aimed to evaluate, what emotions cause threat appeal ads targeting drunk driving and whether these ads change risky driving attitudes. 41 students (17.1 percent males; mean age 20.9 years; 53.7 percent had a driving license) voluntarily participated in the experimental study. Every participant was randomly assigned to one of three groups: two experimental (watched one of two TV ads with threat appeals) or control group (watched car wash ad with no threatening stimuli). After watching one of three ads, all participants were asked to evaluate seven emotions and to fill in Driving Attitude Questionnaire (DAQ). Results revealed that both road safety threat appeal ads targeting drunk driving did not arouse any stronger fear emotions or differences in driving attitudes compared to control group. Both experimental groups didn't differ in emotions or attitudes as well. No difference in emotions and attitudes was found when comparing the reaction of participants who have seen the specific ad before the experiment and those who haven't. The fact of being a licensed driver was also not related to the level of reported emotions or attitude differences in both experimental groups. The study results reveal that the possible effectiveness of threat appeal ads from ongoing social marketing campaigns on reducing drunk driving is questionable and further studies are needed.
\end{abstract}

Keywords: Threat appeal, road safety ad, drunk driving, emotions, attitude towards risky driving.

\section{Introduction}

Drunk driving can cause traffic accidents, injuries, mortality and is called social, financial and one of the biggest problems of the 21st century (Carey \& Sarma, 2016; Sibley \& Harre, 2009; Skorupa, 2014; Sweeney, 2012). According to statistics of the State Enterprise Lithuanian Road Administration, drunk driving led to 308 injuries, 57 death in 2018 and even 351 injuries, 25 death in 2019 on the country's roads. Moreover, traffic accidents due to drunk driving account for about $9-13$ percent of all injuries or deaths on the road in Lithuania (Helmig \& Thaler, 2010) and are named as one of the leading causes of death worldwide (Statistics of traffic accidents in Lithuania; Skorupa, 2014; Sweeney, 2012; Weber, Dillow, \& Rocca, 2011). Concerning sufficiently large and growing numbers of accidents due to drunk driving, it is important to take this problem into account.

Based on research, several measures are most commonly used to reduce drunk driving and its negative outcomes in Lithuania and other countries. One of them is legislation restricting driving under the influence of alcohol and providing strict penalties for offenders (such as loss of one's driving license, license suspension, fines, or jail time) (Zhang, 2014). Social marketing with threat appeals is another commonly used measure and, according to some researchers, more effective in comparison with legislation (Ditsuwan, Veerman, Bertram, \& Vos, 2013; Lewis, Watson, \& White, 2010; Sweeney, 2012; Wakefield, Loken, \& Hornik, 2010). Social ads with threat appeal usually include thought - provoking phrases, emotional music, shocking images (such as wrecked vehicles, blood, victims, injured or dead bodies, etc.) to attract viewers' attention and arouse fear. Road safety literature suggest that fear, aroused by social ad, can encourage reflection about one's driving behavior, influence attitudes towards risky driving, and reduce chances of drunk driving in the future (Helmig \& Thaler, 2010; Lennon \& Rentfro, 2010). Threat appeals were proven to be especially effective for young adults, who have the highest risk to drive under the influence (Janstrup, 2017; McKay - Nesbitt, Manchanda, Smith, \& Huhmann, 2011). However, some studies highlight that not all ads with threat appeals are perceived as threatening and can cause fear, even if it is expected to. According to researchers, ads with threatening stimuli are only 
effective in changing drivers' attitudes and reducing drunk driving behavior when fear is actually aroused, therefore it is important to ensure it (Helmig \& Thaler, 2010; Lennon \& Rentfro, 2010; Phillips, Ulleberg, \& Vaa, 2011; Rhodes, 2017; Weber et. al., 2011).

Four main types of negative consequences are usually shown in social advertisements in order to cause fear emotions: physical consequences such like disease or disability, social consequences such as social exclusion, psychological consequences like failure or loss of self - esteem, and financial consequences such like loss of income or loss of job (Skorupa, 2014; Zhang, 2014). Moreover, depending on the type of negative consequences that are shown in social ad, different levels of fear can be aroused: low, medium or strong. Based on previous research, ads with named possible negative consequences of drunk driving and without any pictures of physically injured people, could be considered as less fearful. Meanwhile those ads, in which injured or dead bodies are shown usually are considered as more threatening (De Pelsmacker, Cauberghe, \&Dens, 2011; Nielsen \& Shapiro, 2009; Sweeney, 2012). De Pelsmacker and colleagues (2011) showed that ads with a strong graphic threat (when a seriously injured traffic victim is shown) can encourage safer driving behavior. Chocking images were found to be effective not only in arousing fear but also in encouraging safer attitudes towards drunk driving and in making drunk driving behavior less likely in the future (Carey \& Sarma, 2016; Lennon \& Rentfro, 2010). Still, the opposite "boomerang effect" stating that threat appeals increase risky behaviour or intentions to involve in risky driving was found too (Carey \& Sarma, 2016). However, it is important to note, that previous studies also had some limitations: used ads that were designed specifically for research or was performed in different countries, which could have affected results. Also, there is still a lack of studies specifically evaluating the level of fear, which is caused by ads shown on national TV channels, and its impact on attitudes towards drunk driving. Additionally, some studies reveal that even when negative consequences, related to drunk driving, are presented, fear emotions do not necessarily arouse (Sibley, Harre, 2009). According to Lennon and Rentfro (2010), such results could be related to ignorance or rejection of social advertisement, when the advertisement's content is perceived as irrelevant by the viewer. For example, when a person doesn't have driving experience or believes that these negative consequences could not happen to him or her (Lewis et. al., 2010; Phillips et. al., 2011) or when a social ad is perceived as boring, not shocking enough or has been seen in the past (Sweeney, 2012; Wakefield et. al., 2010). Thus, even there are some knowledge regarding messages with threat appeals, the results of threat appeal effectiveness remain contradictory.

Despite advertisements with threat appeals are widely used in Lithuania to address drunk driving, no studies of its effectiveness were found. Thus, this study aimed to evaluate, what emotions cause threat appeal ads targeting drunk driving and whether these ads change risky driving attitudes. Based on literature review, it was expected that drunk driving ads with threatening stimuli cause stronger fear and driving attitudes change in comparison with control group, where no threatening stimuli was presented. Likewise, an advertisement, in which physical injuries were presented, was expected to cause stronger fear and greater risky driving attitudes change in comparison with ad, in which no physical injuries were shown. It was also hypothesized that stronger fear can be caused for those participants, who have driving experience and haven't seen the advertisement before the study.

\section{Method}

Participants. Forty-one students participated in the study. 17.1 percent (7) of participants were males and 82.9 percent (34) were females. Participants' age varied from 19 to 25 years (Mean $=20.9$; $\mathrm{SD}=1.7) .22$ (53.7 percent) participants had a driving license and reported driving at least once per week. 18 study participants (19.5 percent) reported having experience of driving under the influence of alcohol and 23 (56.1 percent) participants had have driven with a drunk driver.

Research procedure. Students aged $18-25$ years from one Lithuanian university were invited to participate in the experimental study on voluntary basis. A concrete age group was selected because of provided evidence that young drivers (aged $18-25$ years) have the highest risk to drive under the influence of alcohol in comparison with older drivers (Carey \& Sarma, 2016; Sweeney, 2012; Weber et. al. 2011; Zhang, 2014). The study was approved by the Ethics Committee of Psychology at the Department of Psychology at Vytautas Magnus University. All participants signed the informed consent to participate in the experimental study and were randomly assigned to one of three groups: two experimental and one control group. There were no significant differences for participants' age $\left(\chi^{2}=13.142, \mathrm{p}=.359\right)$, gender $\left(\chi^{2}=1.010, \mathrm{p}=.603\right)$ or driving experience $\left(\chi^{2}=5.212, \mathrm{p}=.266\right)$ between all three conditions. The posttest-only control group design, applicable in similar research, was used for the experiment (Becheur \& Das, 2018; Rait, 2019). Participants received no incentive for participation in the study. 
Stimuli. The independent variable was social ads that apt to reduce or stop drunk driving that differed in terms of threat appeal. Both socials ads targeting drunk driving were created by the Lithuanian Road Administration and used in the study with permission. Participants in the first experimental group watched the road safety ad "Don't drive after drinking - don't become a killer", which shows a schoolboy passing through a pedestrian crossing to his mother, being hit by a drunk driver (expected to arouse the strongest fear). Participants in the second experimental group were presented with the road safety ad "When driving after drinking, death breathes in your back", which shows two young drunk men driving a car, skylarking with loud music on, and a ghost, sitting on the back seat of the car, who is like death breathing to their backs (expected to arouse medium fear). Control group participants saw a car wash advertisement, where only a driving lady was presented with no threatening stimuli (expected to arouse the lowest or no fear). Each video advertisement was approximately 30 seconds long.

Instruments. After watching one of three ads, participants were asked to fill in the anonymous self-reported questionnaire. Participants' fear was measured by seven emotions: fearful, tense, nervous, scared, reassured, relaxed, comforted, which participants had to evaluate on a scale from 1 to 7 (Cronbach's alpha .868) (Maheswaran \& Meyers-Levy, 1990). The level of fear was determined by calculating the sum of ratings (when three positive emotions were reversed). Higher score of the scale indicated higher degree of fear in reaction to the stimuli. Attitudes towards risky driving were assessed with Driving Attitudes Questionnaire (DAQ) (Cronbach's alpha .812) (Starkey, Isler, 2016). DAQ consists of 20 items which participants had to evaluate on a scale from 1 to 5 when higher scores indicated safer attitudes towards risky driving.

The questionnaire also included demographic questions regarding participant's age, gender, driving experience and frequency, accident involvement, and questions about the social ad they watched.

\section{Results and discussion}

First of all, aroused fear and attitudes towards risky driving between experimental and control groups was compared. Descriptive characteristics of fear emotions and attitudes towards risky driving in two experimental and control groups are presented in Table 1. Contrary to expectations, the results of the study showed that both Lithuanian social ads targeting drunk driving did not cause any significant sense of fear compared to control group (accordingly, Mann Whitney $\mathrm{U}_{\text {lexperimental }}=81.00, \mathrm{p}=.485$ and Mann Whitney $\mathrm{U}_{\text {2experimental }}=74.50, \mathrm{p}=.849$ ). Participants' fear after watching a TV ad didn't differ between both experimental groups as well (Man Whitney $U=93.00, p=.629)$.

Table 1. Descriptive characteristics of fear emotions and attitudes towards risky driving in experimental and control groups.

\begin{tabular}{|l|c|c|c|c|c|c|}
\hline \multirow{2}{*}{ Factors } & \multicolumn{2}{|c|}{$\begin{array}{c}\mathbf{1}^{\text {st }} \text { experimental group } \\
(\mathbf{N}=\mathbf{1 6})\end{array}$} & \multicolumn{2}{c|}{$\begin{array}{c}\mathbf{2}^{\text {nd }} \text { experimental } \\
\text { group (N= 13) }\end{array}$} & \multicolumn{2}{c|}{$\begin{array}{c}\text { Control group } \\
\text { (N= 12) }\end{array}$} \\
\cline { 2 - 7 } & $\mathbf{M}$ & $\mathbf{S D}$ & $\mathbf{M}$ & $\mathbf{S D}$ & $\mathbf{M}$ & SD \\
\hline Fear emotions & 30.56 & 8.1 & 29.00 & 11.1 & 28.5 & 7.9 \\
\hline $\begin{array}{l}\text { Attitudes towards risky } \\
\text { driving }\end{array}$ & 71.00 & 10.8 & 71.31 & 9.6 & 73.17 & 9.0 \\
\hline
\end{tabular}

The similar results were obtained when comparing attitudes towards risky driving between both experimental groups and control group (Mann Whitney $\mathrm{U}_{\text {lexperimental }}=78.00, \mathrm{p}=.558$ and Mann Whitney $\mathrm{U}_{\text {2experimental }}=67.00, \mathrm{p}=.549$ ). No significant differences in attitudes were found between first and second experimental groups as well (Mann Whitney $U=97.00, p=.982$ ). Thus, it can be concluded, that threatening appeals targeting drunk driving did not arouse any fear or threat as well was not effective in changing attitudes towards risky driving. Based on these results, perhaps more shocking, threatening images (such as images of blood, injured bodies of victims or real scenes from car accidents, related to drunk driving) are needed in order to arouse fear emotions and reach significant changes in attitudes towards risky driving in young people (Carey \& Sarma, 2016; Lennon \& Rentfro, 2010; Zhang, 2014). It could be that young adults are used to be too often presented with threatening stimuli through computer games, newsletters or films, so no significant fear emotions were aroused (Lennon \& Rentfro, 2010). However, more frightening drunk driving ads could encourage some cognitive changes by drawing their attention to negative consequences related to such behavior and change attitudes towards drunk driving to safer ones (Carey \& Sarma, 2016).

Further, the reactions of participants who saw the specific ad during the experiment for the first time was compared to those who had seen it before in both experimental groups (the comparison is presented in Table 2). Given that there was found no significant differences in emotions and attitudes between both experimental groups, further calculations were performed by combining these groups together. 
Table 2. The comparison of emotions and attitudes, depending on familiarity with advertisements.

\begin{tabular}{|l|c|c|c|c|c|c|}
\hline \multirow{2}{*}{ Factors } & \multicolumn{2}{|c|}{ Have seen $(\mathbf{N}=\mathbf{1 4})$} & \multicolumn{2}{c|}{ Haven't seen $(\mathbf{N}=\mathbf{1 1})$} & \multirow{U}{*}{$\boldsymbol{U}$} & \multirow{2}{*}{$\boldsymbol{p}$} \\
\cline { 2 - 7 } & $\mathbf{M}$ & SD & M & SD & & .913 \\
\hline Fear emotions & 29.29 & 8.0 & 29.00 & 11.1 & 75.00 & .324 \\
\hline $\begin{array}{l}\text { Attitudes towards } \\
\text { risky driving }\end{array}$ & 70.00 & 12.0 & 73.91 & 7.5 & 54.50 & .324 \\
\hline
\end{tabular}

Results also revealed no differences in emotions or attitudes between those participants who have and those who have not seen the ad before the experiment ( $p>.05)$. According to Sweeney, those advertisements that are perceived as threatening and arouse fear remain effective independently how many times it was seen (Starkey \& Isler, 2016). Meanwhile, other authors reveal that messages with threat appeals, seen several and more times, can become boring and no longer arouse fear or encourage attitude changes (Lewis, Watson, White, \& Tay, 2007). Thus, it remains unclear, whether familiarity in advertisements could significantly affect the results and reduce its effectiveness.

Table 3. Differences between drivers and non-driver's emotions and attitudes in two experimental and control groups.

\begin{tabular}{|l|c|c|c|c|c|c|}
\hline \multirow{2}{*}{ Factors } & \multicolumn{2}{|c|}{$\mathbf{1}^{\text {st }}$ experimental group } & $\mathbf{2}^{\text {nd }}$ experimental group & \multicolumn{2}{c|}{ Control group } \\
\cline { 2 - 7 } & \multicolumn{2}{|c|}{ Mean Rank } & \multicolumn{2}{c|}{ Mean Rank } & \multicolumn{2}{c|}{ Mean Rank } \\
\cline { 2 - 7 } & $\begin{array}{c}\text { Drivers } \\
(\mathbf{N}=\mathbf{7})\end{array}$ & $\begin{array}{c}\text { No driving } \\
\text { experience } \\
\mathbf{( N = 6 )}\end{array}$ & $\begin{array}{c}\text { Drivers } \\
(\mathbf{N = 8})\end{array}$ & $\begin{array}{c}\text { No driving } \\
\text { experience } \\
\mathbf{( N = 5 )}\end{array}$ & $\begin{array}{c}\text { Drivers } \\
(\mathbf{N}=\mathbf{7})\end{array}$ & $\begin{array}{c}\text { No driving } \\
\text { experience } \\
(\mathbf{N}=\mathbf{5})\end{array}$ \\
\hline Fear emotions & 6.43 & 7.67 & 7.06 & 6.90 & 8.21 & 4.10 \\
\hline $\begin{array}{l}\text { Attitudes towards } \\
\text { risky driving }\end{array}$ & 4.50 & 9.30 & 6.50 & 7.80 & 5.93 & 7.30 \\
\hline
\end{tabular}

Finally, the impact of being a driver was evaluated (see Table 3). Based on these results, the driving experience was not related to the level of reported emotions (Mann Whitney $\mathrm{U}_{\text {lexperimental }}=17.00$, $\mathrm{p}=.566$; Mann Whitney $\mathrm{U}_{2 \text { experimental }}=19.50, \mathrm{p}=.942$; Mann Whitney $\left.\mathrm{U}_{\text {control }}=5.50, \mathrm{p}=.051\right)$. There were also no significant differences between drivers and non-drivers attitudes in second or control groups (Mann Whitney $U_{2 \text { experimental }}=16.00, p=.942$; Mann Whitney $U_{\text {control }}=13.50, p=.514$ ). However, those participants who had a driving license reported safer attitudes towards risky driving after watching the advertisement with the strongest threatening stimuli compared to those who had no driving license (Mann Whitney $\mathrm{U}_{\text {lexperimental }}=3.50, \mathrm{p}=.018$ ). Having in mind that many researchers stated that attitude changes are led by emotions (Carey \& Sarma, 2016; McKay - Nesbitt et. al., 2011; Nielsen \& Shapiro, 2009; Rhodes, 2017) it could be that participants subjectively did not realize or capture the change of their emotions, even if they were aroused. Findings also highlight that calm and relaxation are natural reactions after threatening stimuli, which could lead to results that ads were not effective causing fear (Algie \& Rossiter, 2010). Thus, it is important to have in mind, that more threatening drunk driving ads could cause stronger fear and encourage bigger attitude changes (Becheur \& Das, 2018; Janstrup, 2017; Wali, Ahmed, Iqbal, \&Hussain, 2017).

\section{Conclusions}

Single watching of specific threat appeal targeting drunk driving could not cause any significant emotional or attitudinal change. Thus, the possible effectiveness of Lithuanian threat appeal ads on reducing drunk driving is questionable and further studies are needed.

\section{References}

Algie, J., \& Rossiter, J. R. (2010). Fear patterns: A new approach to designing road safety advertisements. Journal of Prevention and Intervention in the Community, 38(4), 264-279.

Becheur, I., \& Das, A. (2018). From Elicitation to Persuasion: Assessing the Structure and Effectiveness of Differential Emotions in Anti-Drunk-Driving Campaigns. Journal of Promotion Management, 24(1), 83-102. 
Carey, R. N., \& Sarma, K. M. (2016). Threat appeals in health communication: messages that elicit fear and enhance perceived efficacy positively impact on young male drivers. BMC Public Health, 16(1), 645.

De Pelsmacker, P., Cauberghe, V., \& Dens, N. (2011). Fear appeal effectiveness for familiar and unfamiliar issues. Journal of Social Marketing, 1(3), 171-191.

Ditsuwan, V., Veerman, J. L., Bertram, M., \& Vos, T. (2013). Cost-effectiveness of interventions for reducing road traffic injuries related to driving under the influence of alcohol. Value in health, 16(1), 23-30.

Helmig, B., \& Thaler, J. (2010). On the effectiveness of social marketing - What do we really know?. Journal of Nonprofit and Public Sector Marketing, 22(4), 264-287.

Janstrup, K.H. (2017). Road Safety Annual Report 2017. Technical University of Denmark.

Lennon, R., \& Rentfro, R. (2010). Are young adults fear appeal effectiveness ratings explained by fear arousal, perceived threat and perceived efficacy. Innovative Marketing, 6(1), 58-65.

Lewis, I. M., Watson, B., \& White, K. M. (2010). Response efficacy: The key to minimizing rejection and maximizing acceptance of emotion-based anti-speeding messages. Accident Analysis and Prevention, 42(2), 459-467.

Lewis, I. M., Watson, B., White, K. M., \& Tay, R. (2007). Promoting public health messages: Should we move beyond fear-evoking appeals in road safety?. Qualitative Health Research, 17(1), 61-74.

Maheswaran, D., \& Meyers-Levy, J. (1990). The influence of message framing and issue involvement. Journal of Marketing research, 27(3), 361-367.

McKay - Nesbitt, J., Manchanda, R. V., Smith, M. C., \& Huhmann, B. A. (2011). Effects of age, need for cognition, and affective intensity on advertising effectiveness. Journal of Business Research, 64(1), 12-17.

Nielsen, J., \& Shapiro, S. (2009). Coping with fear through suppression and avoidance of threatening information. Journal of Experimental Psychology: Applied, 15(3), 258.

Phillips, R. O., Ulleberg, P., \& Vaa, T. (2011). Meta - analysis of the effect of road safety campaigns on accidents. Accident Analysis and Prevention, 43(3), 1204-1218.

Rait, E. (2019). No text Is worth dying for: The role of emotion regulation in a distracted driving campaign. Journal of European Psychology Students, 10(2), 1-11.

Rhodes, N. (2017). Fear - appeal messages: Message processing and affective attitudes. Communication research, 44(7), 952-975.

Sibley, C. G., \& Harre, N. (2009). The impact of different styles of traffic safety advertisement on young drivers' explicit and implicit self-enhancement biases. Transportation Research Part F: Traffic Psychology and Behaviour, 12(2), 159-167.

Skorupa, P. (2014). Shocking contents in social and commercial advertising. Creativity Studies, 7(2), 69-81.

Starkey, N. J., \& Isler, R. B. (2016). The role of executive function, personality and attitudes to risks in explaining self-reported driving behaviour in adolescent and adult male drivers. Transportation Research Part F: Traffic Psychology and Behaviour, 38, 127-136.

Statistics of traffic accidents in Lithuania - Eismo ịvykių Lietuvoje statistika (in Lithuanian). Retrieved 12 07, 2020, from: https://kpt.policija.lrv.lt/lt/statistika/eismo-ivykiu-lietuvoje-statistika

Sweeney, K. (2012). A study of the Road Safety Authorities use of fear appeals to communicate a public health message. Letterkenny Institute of Technology.

Wakefield, M. A., Loken, B., \& Hornik, R. C. (2010). Use of mass media campaigns to change health behaviour. The Lancet, 376(9748), 1261-1271.

Wali, B., Ahmed, A., Iqbal, S., \& Hussain, A. (2017). Effectiveness of enforcement levels of speed limit and drink driving laws and associated factors-Exploratory empirical analysis using a bivariate ordered probit model. Journal of Traffic and Transportation Engineering, 4(3), 272-279.

Weber, K., Dillow, M. R., \& Rocca, K. A. (2011). Developing and testing the anti-drinking and driving PSA. Communication quarterly, 59(4), 415-427.

Zhang, X. 2014. The influence of fear and authority on psychological reactance: A study of the effectiveness of public service announcement campaigns on drunk driving prevention among college students. Doctoral dissertation. Iowa: Iowa State University, $62 \mathrm{p}$. 